\title{
Formação de Professores e Inclusão: como se reformam os reformadores?
}

\section{Teacher Education and Inclusion: how the reformers can be reformed?}

\author{
David Rodrigues ${ }^{1}$ \\ Luzia Lima-Rodrigues ${ }^{2}$
}

\begin{abstract}
RESUMO
Existe um grande consenso sobre a necessidade de investir na formação de professores para que se possam desenvolver modelos inclusivos na Educação. A Educação Inclusiva deve ser entendida como uma reforma educacional que, para se realizar, necessita que os professores sejam formados em modelos de ensino e comunicação diferentes dos modelos tradicionais. Com base na avaliação que um grupo de estudantes de mestrado em Educação Especial efetuou do seu curso, este artigo discute algumas concepções teóricas sobre formação de professores (nomeadamente o isomorfismo e a infusão) e quatro aspectos centrais da formação de professores para a Inclusão: conteúdos, estratégias de Ensino Aprendizagem, relação teoria-prática e impacto na vida profissional. Conclui-se que é necessário operar uma reforma aprofundada nos cursos de formação para que as pessoas que neles são formadas possam, elas próprias, vir a ser agentes de mudança na escola.

Palavras-chave: formação de professores; educação inclusiva; educação especial.
\end{abstract}

${ }^{1}$ Professor da Universidade Técnica de Lisboa (aposentado). É Presidente da Pró-Inclusão: Associação Nacional de Docentes de Educação Especial (www.proinclusao.com.sapo.pt). Coordena o Mestrado em Educação Especial da Escola Superior de Educação Jean Piaget de Almada. Contato: dantonio.rodrigues@gmail.com

${ }^{2}$ Professora Auxiliar do ISEIT: Instituto Superior de Estudos Interculturais e Transdisciplinares de Almada. Coordena a Especialização em Educação Especial da Escola Superior de Educação Jean Piaget de Almada. É membro fundador da Pró-Inclusão: Associação Nacional de Docentes de Educação Especial. Contato: luzialima-rodrigues@hotmail.com 


\begin{abstract}
There is large consensus about the need of a strong investment in teacher education in order that Inclusive Education can be implemented in regular schools. Inclusive Education must be understood as an educational reform. In order to develop this reform we need that teachers (either "regular" and "specialist") be educated to use teaching and communication paradigms different from those used on traditional schools. Using the data of an evaluation procedure of a master's degree course on Special Education done by its students, this paper discusses some of the theoretical basis of Teacher Education (namely isomorphism and infusion). Then, four aspects of teacher education are discussed: contents, teaching and learning strategies, theory-practice relation and professional impact of the course. The main conclusions can be summarized on the need of development of a deep reform on the courses of teacher Education to make them able to change the values and practices of their students in order to make them active participants on the Inclusive Education reform.
\end{abstract}

Keywords: teacher training; inclusive education; special education.

Não há, não, Duas folhas iguais em toda a criação. Ou nervura a menos, ou célula a mais Não há, de certeza, duas folhas iguais.

GEDEÃO, António (1958)

\title{
Introdução
}

A UNESCO (Organização das Nações Unidas para a Educação, a Ciência e a Cultura) publicou recentemente um importante documento onde se afirma:

Um conceito alargado de Educação Inclusiva pode ser concebido como um princípio e uma orientação geral para fortalecer a educação, com vista a um desenvolvimento sustentável, aprendizagem ao longo da vida para todos e acesso igual de todos os níveis da sociedade às oportunidades de aprendizagem. (UNESCO, 2008) 
Como tem sido realçado por um grande conjunto de autores, a Educação Inclusiva (EI) é uma reforma educacional que abarca um âmbito muito alargado e diferentes níveis de mudanças. A latitude desta reforma pode ser confirmada pela própria definição da UNESCO, apresentada acima, quando são usadas expressões como "alargado", "geral" e "todos os níveis da sociedade". Assim, o objetivo da EI não se resume a uma mera mudança curricular ou mesmo a permitir o acesso de alunos com condições de deficiência à Escola Regular: trata-se de uma reforma bem mais profunda abrangendo os valores e as práticas de todo o sistema educativo tal como ele é comumente concebido.

$\mathrm{Na}$ verdade, a reforma é o destino da Educação. Desde a existência de escolas tal como hoje as concebemos, fundadas no início do século XIX, a escola sempre viveu imersa nas mais diversas reformas. Frequentemente, o ritmo destas reformas foi até rápido demais e, por exemplo, em Portugal, algumas delas não vigoraram o suficiente para serem avaliadas e mesmo plenamente desenvolvidas. A reforma que a EI propõe deve ser considerada como global e profunda, desenvolvida ao longo de um processo que necessita investimento e tempo para se consumar plenamente. Outro aspecto a ter-se em consideração para o desenvolvimento desta reforma é o fato de ela ter como palco escolas que não sentem a necessidade de mudança ou a urgência da reforma; é, muitas vezes, um movimento que surge como "exterior".

Alguns fatores têm sido identificados como sendo essenciais para o desenvolvimento da EI em Escolas Regulares. Booth e Ainscow (2001) apontam as políticas, as práticas e as culturas como aspectos centrais da reforma inclusiva. Quando se perspectiva um cenário de mudança em Educação, há duas questões fundamentais que importa responder: 1) quem serão os agentes, os catalisadores desta mudança; 2) como esta mudança será gerida e planejada.

A resposta à primeira questão realça o trabalho e o papel do professor. Certamente que é importante a ação e a participação dos decisores políticos, dos líderes da comunidade, das famílias, dos próprios alunos, enfim, de todas as pessoas que estão ligadas à escola; mas o papel dos professores enquanto profissionais dotados de uma assinalável autonomia e possibilidade de opção é fundamental. Os professores não são "funcionários", no sentido de um profissional inserido numa cadeia hierárquica e burocrática e que tem de seguir instruções precisas e estritas. Os professores não podem também ser encarados como "técnicos", no sentido em que eles não se movimentam numa profissão que exerce uma prática inquestionável, resolvendo através de metodologias claras os problemas que se lhes deparam. A profissão de professor é bem mais complexa e global: na verdade, trata-se de lidar com a gestão de um currículo, o que implica uma multiplicidade de opções e caminhos possíveis. 
Em relação à segunda questão, gerir e planejar implica autonomia e possibilidade de opção; implica que o professor tem de tomar decisões sobre várias possibilidades de desenvolver o seu trabalho. Esta autonomia tem uma consequência muito importante: é que se o professor puder optar, ele só irá adotar as mudanças que acredita serem efetivamente justas e úteis para o seu trabalho. Um professor com uma grande experiência profissional costumava dizer que

a vitória mais importante de qualquer reforma educativa é vencer o poder da porta da sala de aula. E explicava: Se o professor não estiver profundamente convencido da utilidade e justiça de qualquer reforma educacional, ele poderá sempre usar a porta da sala para deixar a reforma no corredor. Também poderá fechar a porta para pôr em prática reformas que não estão oficializadas. (RODRIGUES, 2008).

Os professores devem, pois, ser encarados como parceiros fundamentais para iniciar e desenvolver qualquer reforma educacional. Como essa mudança deve ser "pilotada" para ser eficaz? É este o tema central deste artigo. Usando comentários avaliativos feitos por estudantes de um curso de mestrado em Educação Especial, discutiremos as práticas e valores da formação de professores em Educação Especial e Inclusiva. Por fim, apresentaremos alguns princípios que, emergindo do trabalho empírico, parecem mais importantes para o desenvolvimento de políticas adequadas de formação de professores.

\section{Professor: uma profissão de desafio}

A investigação sobre Formação de Professores tem realçado a importância de diversas variáveis e atributos que o professor deverá possuir para ser bem sucedido na sua profissão. Num estudo clássico desenvolvido por Shulman (1986) foram apontadas três características que parecem ser mais determinantes para o sucesso da profissão docente: as capacidades (habilidades, propensões e conhecimento), as ações (atividades, desempenho e comportamento) e os pensamentos (cognição, metacognição e emoções).

Estas capacidades, ações e pensamentos devem ser usados em campos de aplicação muito diversos. Os professores são, atualmente, chamados a dominar 
e a ensinar um conjunto de conhecimentos e matérias que acompanham a complexidade da informação e conhecimento que caracterizam as sociedades contemporâneas. As escolas tornaram-se verdadeiros fóruns em que, à semelhança do que se passa na sociedade, multiplicam-se e entrecruzam-se conhecimentos. As escolas desenvolvem múltiplos projetos (ex: cidadania europeia, prevenção rodoviária, estilos de vida ativos, educação sexual etc.) que são acrescentados ao já dilatado currículo formal. Trata-se, sem dúvida, de uma enorme solicitação aos professores que levou Ben Peretz (2001) a considerar que ser professor é uma "missão impossível" devido à complexidade de capacidades, ações e conhecimentos que o professor necessita dominar na sua profissão.

Muitas das áreas de ensino que têm sido introduzidas nas escolas desafiam as competências do professor. Uma destas é certamente a de Tecnologias da Informação e Comunicação (TIC). O que se pede hoje ao professor não é simplesmente que ele use o computador para processamento de texto ou apresentação de conteúdos, mas para usos mais sofisticados das TIC, tais como plataformas de e-learning, pesquisa em sites de bases de dados especializados, compartilhar fluentemente documentos e conhecimento pela internet. Outra destas novas áreas de competência é o uso de métodos ativos e expressivos e que valorizem e incentivem a investigação dos alunos. Os professores são chamados a ser proficientes no trabalho com grupos e no uso de estratégias interativas. Adicionalmente, são ainda chamados a desenvolver todas estas novas estratégias numa perspectiva inclusiva, querendo isto dizer que se espera que a sua intervenção promova a equidade social e que, assim, recuse a exclusão tanto no acesso como no sucesso de qualquer estudante. Todo este trabalho, para ser eficaz, necessita de ser desenvolvido em cooperação com outros docentes e técnicos, promovendo projetos de base interdisciplinar e com ligação à comunidade (RODRIGUES, 2007). Trata-se, sem dúvida, de um enorme conjunto de desafios.

No que respeita a esta última solicitação aos professores - desenvolver projetos dentro de uma perspectiva de Educação Inclusiva - é interessante notar que algumas das competências que antes eram do domínio exclusivo dos professores de Educação Especial ou das escolas especiais, "migraram" para as escolas e professores regulares. Espera-se, assim, que o professor (mesmo com pouca ou nenhuma supervisão ou ajuda) seja capaz de responder a um largo espectro de problemas que, ainda há bem poucos anos, seriam da competência estrita de técnicos ou professores especializados (HOPPEY; YENDOL-SILVA; PULLEN, 2004). Podem ser dados alguns exemplos destas competências que são agora do professor regular: trabalho com alunos com dificuldades num contexto de grupo, ensinar alunos com condições de deficiência, trabalhar com alunos com déficits de atenção etc. Fisher, Frey e Thousand (2003), ao estudarem as tarefas que os professores de Educação Especial necessitam desempenhar em 
ambientes inclusivos, mencionam o ensino, a avaliação do aluno e a avaliação do ensino, o que mostra que também os professores de Educação Especial são chamados a assumir competências que antes não eram deles.

Todas estas solicitações novas e desafiadoras nos interrogam sobre qual é o conhecimento que o professor deve adquirir e dominar para enfrentar em toda a sua extensão. Como foi dito, algumas destas competências dos professores de Educação Especial "migraram" para as competências dos professores regulares atuando em contextos inclusivos. Este fato aumentou o já de si extenso leque de solicitações a que o professor da Escola regular deve dar resposta.

\section{Formação de Professores para Educação Especial em Portugal}

Nas últimas décadas, Portugal tem desenvolvido políticas educacionais conducentes à Inclusão. A Lei publicada em Janeiro de 2008 (Decreto-Lei 3/2008) renova o compromisso com a Educação Inclusiva que tinha sido assumido na legislação publicada em 1997. Em 2006, foi criado um quadro de professores de Educação Especial em cada Agrupamento de Escolas, o que permitiu a maior continuidade e a identidade dos serviços na escola. Os Professores de Educação Especial são parte integrante dos recursos humanos da Escola e integram-se no espectro de respostas que a Escola pode encontrar para alunos com dificuldades. As últimas estatísticas disponíveis (DGIDC, 2009) apontam para a existência de 4779 professores de Educação Especial em escolas regulares. Existem 31.776 alunos com NEE (Necessidades Educativas Especiais) com um Plano Educativo Individual nas escolas regulares. Nas escolas especiais são educados 2.382 alunos. Estes números dão conta de uma realidade educativa em que a inclusão se assume como a resposta largamente preferencial para a educação de alunos com NEE.

Com as mudanças que o Tratado de Bolonha implicou na harmonização do sistema de Educação Superior na Europa, a Formação de Professores sofreu importantes reformas. A formação de qualquer professor em Portugal, atualmente, passa por um total de cinco anos de estudos superiores, organizados em dois ciclos: um $1^{\circ}$ Ciclo com seis semestres (licenciatura em Matemática, História, Pré-escola) e um $2^{\circ}$ Ciclo com três ou quatro semestres (Mestrado em ensino de Matemática, História, Pré-escola). Somente depois deste $2^{\circ}$ Ciclo concluído é que o profissional é considerado "professor" e pode assumir autonomamente uma turma ou classe. 
No caso da Educação Especial, esta é considerada uma "especialização" docente e pode ser cumprida quer em cursos de "Especialização em Educação Especial" (2 semestres) ou na frequência e aprovação da parte curricular do Mestrado em Educação Especial (2 semestres), incluindo por vezes um "Trabalho de Projeto" com características de capacitação profissional. Acontece que, de acordo com a legislação vigente, é considerado especialista em "Educação Especial" o professor que, na data do ingresso ao curso de especialização, tenha pelo menos cinco anos de serviço docente. Assim, hoje, para ser professor de Educação Especial, o caminho é: $1^{\circ}$ Ciclo (180 Créditos, em 6 semestres $)+2^{\circ}$ Ciclo ( 90 ou 120 Créditos, em 3 ou 4 semestres) + cinco anos de serviço docente + especialização/parte acadêmica do mestrado (60 Créditos, em 2 semestres). É, sem dúvida, uma longa carreira de formação.

Em 2005, só 40\% dos professores de Educação Especial em exercício nas Escolas portuguesas tinham obtido um curso de especialização nesta área. Atualmente, a situação é identificada como sensivelmente melhor em termos de qualificação, mas o problema da falta de especialização dos professores permanece uma das matérias que merece atenção.

A Formação de Professores em Educação Especial é atualmente oferecida por um conjunto de escolas politécnicas e universidades tanto públicas como privadas. Estes programas, de acordo com a lei portuguesa, têm que ter a duração mínima de 250 horas e funcionar no período mínimo de 22 semanas letivas. O organismo do Ministério da Educação que supervisiona a formação especializada - o Conselho Científico-Pedagógico da Formação Contínua - determina que os cursos de especialização em Educação Especial podem ser organizados em seis domínios: 1. Cognitivo-motor; 2. Emocional e da Personalidade; 3. Audição e Surdez; 4. Visão; 5. Comunicação e Linguagem; e 6. Intervenção Precoce. A organização curricular destes cursos está também legislada: os cursos devem incluir uma componente de Ciências da Educação (mínimo de 50 horas), uma componente específica sobre a área de especialização do curso (não menos que $60 \%$ do número total de horas) e uma componente ligada à preparação, desenvolvimento e avaliação de um projeto na área de especialização (mínimo de 40 horas). Encontra-se ainda legislado que pelo menos $70 \%$ dos professores do curso devem ser detentores de um grau de Mestre ou Doutor.

Existe um perfil das competências que o Professor de Educação Especial deve dominar. Estas competências são: 1. Análise crítica; 2. Intervenção; 3. Formação de professores, supervisão e avaliação; e 4. Consultoria.

Os professores de Educação Especial (assim designados na nomenclatura oficial) trabalham em Escolas regulares no desenvolvimento de projetos de inclusão e este aspecto tem vindo a ser apontado, por exemplo, pela Pró-Inclusão: Associação Nacional de Docentes de Educação Especial, como um aspecto que 
dificulta um perfil de intervenção claro desses professores, uma vez que se espera que eles só trabalhem com alunos com condições de deficiência, ainda que a solicitação da escola seja bem mais ampla, solicitando apoio para todos os alunos que apresentam dificuldades significativas no seu processo de aprendizagem.

\section{Processo empírico}

O objetivo deste estudo foi analisar as respostas de alunos de um curso de especialização em Educação Especial sobre questões específicas relativas à sua formação. Estas questões centraram-se em quatro aspectos: relação teoria-prática, conteúdos, estratégias e impacto do curso na vida profissional.

A amostra foi constituída por 35 estudantes recém-formados por um curso de especialização em Educação Especial, que responderam, em Junho de 2008, a um questionário aberto e que tinha como objetivo avaliar algumas dimensões do curso realizado. Destes 35 estudantes, 4 eram do gênero masculino e os restantes do gênero feminino. 29 tinham prática docente de cinco anos no ensino regular, 22 já tinham experiência em Educação Especial, tanto em escolas especiais como em escolas regulares e dois alunos não eram professores.

O questionário era constituído por 4 blocos de questões referentes a 4 dimensões: 1. Avaliação dos conteúdos ministrados durante o curso; 2. Estratégias de ensino-aprendizagem; 3. Relação teoria-prática; e 4. Impacto do curso nas atitudes e práticas.

O enunciado do questionário pedia explicitamente que fossem mencionados exclusivamente os fatores que cada aluno achasse mais importantes, podendo, inclusive, enumerá-los. Para cada uma das perguntas era pedido que se pronunciassem sobre 3 aspectos: os que consideravam mais positivos, os que consideravam menos positivos e, por fim, uma sugestão de melhoria.

Os dados foram tratados agrupando as respostas em 12 clusters conteudísticos referentes a cada um dos 4 domínios perguntados e os 3 aspectos mencionados dentro de cada um.

Trata-se de um estudo exploratório em que, de forma eminentemente descritiva, avaliam-se 4 dimensões do curso: 1. Conteúdos (os conteúdos que foram julgados mais marcantes e úteis); 2. Estratégias de Ensino-Aprendizagem (as estratégias que foram usadas ao longo do curso que foram julgadas mais significativas para a formação); 3 . Relação Teoria-Prática (como foram articulados com a prática os conhecimentos teóricos); e 4. Impacto profissional (que tipo de experiências foram julgadas mais úteis para a vida profissional como professores de Educação Especial) 


\section{Apresentação/discussão dos resultados}

Durante a vida profissional de um professor existem momentos de aprendizagem que têm uma influência direta na qualidade do seu ensino. No entanto, muitos professores afirmam que não foi a sua educação formal como professores que mais influenciou as mudanças mais importantes na sua carreira. A prática reflexiva, o trabalho cooperativo, a inclusão num projeto da Escola ou da comunidade, são exemplos citados como experiências que desempenham um papel decisivo nas competências e atitudes face à profissão. Existem, no entanto, muitos professores que identificam a formação inicial ou em serviço como decisivas para o desenvolvimento das suas atitudes e competências como profissionais.

A formação inicial de professores é um período crítico e, sem dúvida, importante para a ocorrência destas mudanças. Algumas razões contribuem para a importância deste período: 1) a duração e o objetivo do plano de estudos; 2) a diversidade de experiências, tanto teóricas como práticas, que são proporcionadas ao aluno; e 3) a planificação mais ou menos estruturada deste processo. O período da formação inicial de professores é decisivo para adquirir e mudar um largo conjunto de práticas e valores. E citaríamos um exemplo pessoal: costumamos pedir aos nossos estudantes de mestrado, nas primeiras aulas do curso, que escrevam um texto intitulado: "o meu melhor professor". Esta descrição detalhada do "melhor professor" de cada um é guardada e, no fim do curso, volta a ser apresentada e comentada. Esta estratégia é usada com dois objetivos principais: 1) tornar os estudantes conscientes que o "melhor professor" que eles descrevem é o professor que eles gostariam de ser e, portanto, implica uma perspectiva reprodutiva e conservadora; e 2) discutir como este "melhor professor" encararia, hoje, os desafios da educação contemporânea, nomeadamente a Educação Inclusiva.

Assim, a formação inicial é um momento privilegiado para uma ruptura nesta cadeia de reprodução (e.g., ensinar da forma como se foi ensinado). Se os valores dos estudantes não forem desafiados por novos conhecimentos, novas experiências de aprendizagem e de ensino, pelo contato com alunos singulares etc., estes alunos terão, certamente, a tendência de seguir e reproduzir os valores segundo os quais eles próprios foram educados. A formação inicial ou especializada é, pois, um período de possibilidade de interrupção desta lógica reprodutiva.

Apresentaremos e discutiremos, a seguir, os dados sobre as quatro dimensões questionadas: 


\section{Conteúdos}

É possível organizar os conteúdos dos cursos de formação de professores de Educação Especial segundo dois tipos de concepções: a) as que afirmam que existe um conjunto específico de conhecimentos e habilidades para se trabalhar com crianças "especiais"; e b) as que defendem que, dado que a inclusão não se destina só a crianças “especiais", a formação de professores deveria focalizar-se na melhoria global do ensino e da aprendizagem e, assim, formar os professores para reduzir as barreiras à aprendizagem e à participação de todos os alunos (FLORIAN; ROSE, 2009).

Organizar a formação de professores de acordo com uma perspectiva mais "restrita" ou "holística" é uma opção ou mesmo um dilema (KATZ; RATHS, 1992). Em Portugal, o modelo prevalecente de educação é o que enfatiza a melhoria da aprendizagem e da participação de forma "holística". Esta opção pode ser justificada por dois tipos de razões: em primeiro lugar, muitas escolas que oferecem cursos especializados em Educação Especial não têm, efetivamente, um corpo docente suficientemente especializado no campo da Educação Especial. Assim, os cursos são organizados realçando modelos de melhoria da gestão da sala de aula, valores inclusivos, trabalho de grupo, diferenciação curricular, ensino cooperativo, trabalho comunitário e com as famílias etc. Estas áreas podem ser ensinadas por professores oriundos de domínios mais generalistas da Educação. A segunda razão é que os professores de Educação Especial, em Portugal, não usam, de forma sistemática (exceto em meios muito restritos), métodos específicos comumente adotados pela Educação Especial, tais como a análise aplicada do comportamento, o ensino direto, a avaliação formativa, estratégias mnemônicas, desenvolvimento sensorial, desenvolvimento perceptivo-motor, desenvolvimento psicolinguístico, treino de habilidades sociais etc. (BURNS; YSSELDIKE, 2009). Este uso não sistemático de modelos específicos na Educação Especial foi também identificado nos Estados Unidos, onde muitos professores entrevistados disseram que "tiveram que escolher sozinhos os seus próprios métodos de ensino" (BOARDMAN et al., 2005). Este mesmo estudo mostrou que os professores de Educação Especial eram mais sensíveis a assuntos como "a falta de acesso a oportunidades de desenvolvimento profissional" e "a falta de materiais" do que "ao uso, na sua sala de aula, de práticas baseadas na investigação".

Estes modelos "holísticos" e "baseados na sala de aula" conduziram a opções mais centradas nas "heurísticas" do que nas "metodologias" de ensino. Desta forma, os problemas da inclusão são abordados como se fossem "singu- 
lares - cada caso é um caso". O modelo heurístico da intervenção do professor (significando que esta é organizada por aproximações sucessivas e entendimentos temporários de uma situação assumida como complexa) convida, pela sua assumida incerteza, ao trabalho de grupo e ao ensino cooperativo de forma a encontrar, através de múltiplas contribuições, as possibilidades mais adequadas para trabalhar com alunos com dificuldades.

No entanto, este modelo "holístico" apresenta igualmente alguns aspectos problemáticos. Um deles é a reduzida quantidade de informação que eles têm que dominar. A ênfase na compreensão e na avaliação de situações complexas é, muitas vezes, obtida em detrimento de um conhecimento mais sistematizado do campo de estudo. Damos um exemplo: há algum tempo, pedimos a estudantes de mestrado em Educação Especial para fazerem um "dever de casa": decorar um soneto. Eles deveriam fazê-lo e, ao mesmo tempo, escrever um pequeno relatório sobre as estratégias que tinham usado para realizar esta tarefa de memorização. A experiência foi realmente muito interessante e proporcionou um rico material para discussão. Quando chegou o dia da apresentação dos trabalhos, quatro estudantes disseram-me que não tinham sido capazes de memorizar o poema. Outros três disseram-nos que tinham conseguido memorizar o soneto, mas que não eram capazes de recitá-lo em frente aos seus colegas. A reflexão sobre os diferentes relatórios feitos pelos alunos foi muito rica, no sentido em que evidenciou diversas e inesperadas estratégias de memorização. Mas um importante "efeito colateral" desta experiência de aprendizagem foi que alguns alunos não possuíam capacidades suficientes para "estudar e memorizar". Muitos deles atribuíram este fator ao fato de todo o seu percurso escolar ter sido efetuado segundo modelos mais "holísticos". Concluíram que muitos dos seus professores anteriores nunca verificaram, efetivamente, qual era o seu real conhecimento sobre assuntos específicos e da bibliografia que lhes tinha sido dada como fundamental.

Durante muitos anos muito conhecimento foi produzido e a experiência no campo da Educação Especial foi sistematizada. Seria certamente muito imprudente negligenciar toda esta quantidade e qualidade de experiência e conhecimento. Mas é importante que este acervo de conhecimento seja usado num enquadramento atual, isto é, num enquadramento de inclusão. A dificuldade de usar este conhecimento em contextos inclusivos é manifesta, por exemplo, quando se equaciona uma colaboração entre as escolas regulares e as escolas "especiais" (estas, atualmente, em Portugal, em processo de conversão para "Centros de Recurso para a Inclusão"). Os professores das escolas regulares tendem a sobrestimar a participação dos colegas "especializados" e dos técnicos dessas escolas especiais (psicólogos, terapeutas etc.). O argumento é que "estes técnicos sabem muito sobre as deficiências". A surpresa, quando os contatos 
são estabelecidos, é o conhecimento tão restrito que os técnicos das escolas especiais têm sobre o processo de funcionamento de uma escola regular que procura organizar-se em termos inclusivos. Assim, precisamos, sem dúvida, de criar ambientes de efetiva cooperação porque, tanto os professores das escolas regulares como os professores e técnicos das escolas especiais têm conhecimentos incompletos, mas complementares.

\section{Estratégias de ensino-aprendizagem}

Recentemente (RODRIGUES; LIMA-RODRIGUES, 2011) defendemos que a formação de professores, tanto quanto possível, deve ser "isomórfica", ou seja, que os estudantes devem ser formados passando por estratégias e metodologias semelhantes àquelas que eles usarão como profissionais. $\mathrm{O}$ conhecimento de um professor sobre, por exemplo, como pode uma determinada disciplina ser ensinada de forma personalizada, é muito diferente se ele tiver tido uma experiência pessoal e bem sucedida com esta metodologia de ensino. Frequentemente os alunos, depois de estudarem textos sobre a aprendizagem personalizada, perguntam: “como é que se usa este método na prática?". É óbvio que os métodos de ensino baseados no estudo de textos não são suficientes para que os alunos possam dominar um determinado conteúdo de ensino ou desenvolver uma competência prática/instrumental própria da docência. Alguns estudantes da nossa amostra referiram que a experiência mais significativa que tinham tido sobre "aprendizagem personalizada" foi numa dinâmica que aconteceu durante o curso, em que o grupo aprendeu um determinado conteúdo pesquisando em diversas fontes de informação e aprendendo em diferentes grupos (grande grupo de projeto; grupo de nível; trabalho em pares; trabalho individual). Quando se fez a avaliação desta experiência, os estudantes afirmaram que tinham compreendido o conceito de "aprendizagem personalizada" e que se sentiam capazes de usar métodos semelhantes com os seus alunos. "A questão mais importante para usar a aprendizagem personalizada é não só conhecer os alunos e o que eles sabem, mas conhecê-los como pessoas".

Outra opinião dos inquiridos sobre as estratégias de ensino é que as oportunidades de trabalho cooperativo necessitam de ser mais bem preparadas e planejadas: "por vezes o trabalho de grupo que é proposto não é suficientemente desafiador a todo o grupo. Um dos elementos do grupo poderia fazê-lo sozinho. Sentimo-nos subestimados". Os inquiridos recomendaram que fossem incluídas, no curso, experiências de aprendizagem personalizada, trabalho de grupo, tarefas multinível, gestão de grupos heterogêneos, estratégias de negociação etc. Foi 
também realçada a importância de se passar pela experiência de comprometimento com estratégias ativas e não só de análise e discussão de textos teóricos.

\section{Relação teoria-prática}

Adotar o princípio do "isomorfismo", citado acima, implica assumir, por exemplo, que os ambientes criativos são os mais adequados quando se quer ensinar futuros professores a promover a criatividade nos seus futuros alunos. Ser ensinado através de estratégias, de metodologias, de climas de aprendizagem e de técnicas, em tudo semelhantes às que a profissão vai exigir, é um instrumento eficaz para a formação de professores.

De acordo com as opiniões dos estudantes em formação, no entanto, parece existir uma incongruência entre os programas da formação de professores e as competências profissionais que se desejam alcançar. Frequentemente, as Escolas Superiores de Educação e as Universidades usam métodos tradicionais (expositivos) de ensino, esperando que os futuros professores, quando assumirem funções docentes, ajam de uma maneira radicalmente diferente daquela em que foram ensinados. Por exemplo, os cursos de formação de professores promovem o trabalho individual, mas, no entanto, esperam que os futuros professores sejam proficientes na utilização de estratégias de trabalho de grupo. Promovem a competição entre os estudantes esperando que eles dinamizem, como profissionais, o trabalho cooperativo. Selecionam a leitura de determinados textos de livros e revistas da especialidade, esperando que os estudantes sejam hábeis no uso de estratégias de investigação. "Não ficou muito claro, para mim, qual a vantagem do trabalho de grupo para a aprendizagem”. Assim, o isomorfismo significa que os cursos de formação de professores devem ser concebidos de forma a ensinar os seus estudantes, usando estratégias e experiências semelhantes àquelas que se espera que eles venham a usar como profissionais. "Aprendi o que era 'aprendizagem personalizada' no curso, mas não faço ideia de como a posso usar em classes em que eu seja o único professor".

\section{Impacto na vida profissional}

A Formação de Professores é um ponto de viragem no desenvolvimento profissional da pessoa. Os professores têm valores, atitudes e concepções sobre 
a prática profissional muito antes de começar estes cursos. De certo que estes valores não são fixos e se irão alterar ao longo da sua vida profissional, mas o momento da "imersão" na sua educação profissional é crucial para se fazer uma escolha fundamentada sobre as opções profissionais. Sem este momento, os professores reforçam o papel reprodutivo ensinando, sobretudo, da forma como foram ensinados. Esta possibilidade é pouco adequada, sobretudo se levarmos em conta as extensas mudanças nos conteúdos, nas capacidades, nos métodos que, entretanto, surgiram desde que estes estudantes iniciaram a escolarização. Assim, este período deve ser vivido plenamente de forma a influenciar os estudantes para serem capazes de iniciar, implementar, sustentar e avaliar reformas educacionais que possam conduzir ao aprofundamento de valores e práticas inclusivas. É largamente conhecido que os professores, ao longo da sua vida profissional, passam por diferentes fases: sobrevivência/descoberta, estabilização, experimentação, serenidade/conservadorismo e descompromisso (sereno ou amargo) (HUMERMAN, 1989). Ora, é justamente na fase de "estabilização" que, de acordo com o modelo de formação em vigor em Portugal, começaria a especialização em Educação Especial (ou seja, 5 anos após o início do trabalho como professor), o que torna ainda mais relevante este momento estruturado e significativo de mudança.

\section{Discussão/recomendações}

Converter o período de formação num período de mudança para paradigmas mais inclusivos, na nossa perspectiva e segundo as opiniões que recolhemos na amostra questionada, implica quarto aspectos centrais.

1. Adoção de uma atitude de investigação como estratégia de formação. Atitude de investigação significa que os estudantes devem aprender a usar os dados de investigação para adquirir e construir o conhecimento de que necessitam. Ainda que não sendo exclusivo dos cursos de formação de professores, este princípio é particularmente útil por duas razões: 1. A formação de professores lida com comportamentos humanos e outras realidades complexas, tal como valores sociais e científicos bem como com metodologias para melhorar a aprendizagem. É pouco provável que uma metodologia possa, por si só, ser eficaz numa tão diversa realidade. Assim, a investigação assume-se como o meio de manter o profissional atualizado numa tão volátil realidade; 2 . A utilização de estratégias baseadas na investigação é um indicador de que os professores serão capazes de usar estratégias similares durante a sua vida profissional. 
Para isso é importante que, para cada tópico de aprendizagem exista um "conhecimento básico" e "linhas de desenvolvimento" onde os estudantes se familiarizem com livros, artigos de revistas da especialidade, pesquisas na internet, trabalhos de campo com observação ou entrevistas, estudos de caso etc. Um professor preparado para usar dados de investigação será certamente capaz de melhor cuidar do seu desenvolvimento profissional. "Durante o curso não tive tempo para estudar tudo o que me foi dado, mas sei onde posso ir buscar a informação que preciso". Jones (2009) mostrou que quando se apresentam aos professores situações inabituais, ou que eles sentiam que o que sabiam não era suficiente para lidar com a situação, eram nesses momentos que o recurso aos dados da investigação se tornava mais premente. É este o tipo de competência que a "atitude de investigação" deve promover.

2. Práticas reflexivas. A existência de momentos reflexivos sobre a própria prática é extremamente importante. Como foi dito antes, a reflexão encontra-se ligada a uma atitude de investigação de permanente questionamento sobre a qualidade das experiências vividas pelo professor. A atitude reflexiva é sintetizada na frase paradigmática de Kats (1995): “O professor tem de ser um estudante do seu próprio ensino". A existência destes momentos reflexivos entre grupos de professores constitui um poderoso instrumento de melhoria para uma crescente adequação do ensino à aprendizagem de alunos com dificuldades e para o uso de estratégias inabituais de aprendizagem. Parrilla e Daniel (2003) encontraram resultados muito positivos a partir de grupos de professores que criam laços de trabalho e que, assim, conseguem resolver muitos dos problemas reais que, sozinhos, não conseguiriam enfrentar. Os grupos de apoio de professores (por vezes também designados por "redes") são uma combinação de ação, reflexividade e cooperação desenvolvidos na lógica da escola. Na mesma linha de atuação podemos encontrar o trabalho de Wasburn-Moses e Rosenberg (2008), que constataram que a criação de redes de apoio entre professores, pais e alunos promove uma melhor adaptação de professores iniciantes e aumenta as suas crenças nas capacidades dos alunos. Durante o período de formação, a reflexão conjunta desempenha um papel muito importante, sobretudo no que respeita à prática supervisionada nos momentos subsequentes ao contato com situações reais. Os professores habituados a refletir em conjunto mostram uma melhor tolerância ao erro, certamente porque se sentem mais confiantes e capazes de encontrar caminhos alternativos e de resolver eventuais problemas. Citamos a frase de um experiente professor que nos disse: "quando se reflete em conjunto, não se encontra " a" solução, mas avaliamos as soluções possíveis e escolhemos a que nos parece menos má". 
3. Relação entre teoria e prática. Quando este assunto é trazido à tona, é comum vermos citada a famosa frase de Kurt Lewin: "não há nada mais prático que uma boa teoria". Entretanto, a questão que nos fica é: "qual é o lugar da prática (e da boa prática) na formação de professores?" Os estudos de caso, relatórios, vídeos, entrevistas, relatos de experiência são parte de um valioso patrimônio de "práticas" que são essenciais para dar confiança aos jovens professores, de forma a lidarem com situações inesperadas. O contato com situações "reais" (no sentido de se referirem a experiências que efetivamente se passaram) é um dos fatores que foi mais valorizado pelos inquiridos no presente estudo. "Gostaria de ter tido uma experiência de trabalho direto com alunos com dificuldades, em lugar de ter só observado vídeos". A ligação entre a teoria e a prática é algo muito valorizado pelos estudantes em formação. A pergunta "como é que este conhecimento se aplica na prática?", frequentemente colocada pelos alunos, não deve ser sobrestimada nem negligenciada. Não ser sobrestimada no sentido em que os estudantes devem ser alertados para o fato de que uma determinada situação tem muitas formas e pontos diferentes de análise. Analisar uma dada realidade não é mais do que usar certos valores para organizar o problema e as possíveis soluções. A prática é, assim, guiada por um conjunto de opções e não deve ser confundida com uma técnica ou uma metodologia inquestionável. Por outro lado, a pergunta não deve ser negligenciada no sentido em que a possibilidade de uma intervenção supervisionada permite a sua harmonização com o conhecimento mais teórico e valoriza (e/ou aumenta) a autoconfiança do estudante para resolver situações novas e complexas na sua vida profissional. Sharma, Forlin e Loreman (2008) compararam as atitudes face à inclusão de 603 professores em formação de quarto países diferentes e concluíram que os estudantes que têm oportunidade de lidar diretamente com as suas preocupações têm atitudes mais positivas face à inclusão de alunos com NEE nas suas salas de aula do que os seus colegas que não tiveram essa componente na sua formação.

4. Contato com situações práticas. A formação de professores não deve esquecer a importância das atitudes dos professores para o sucesso da sua intervenção. É fundamental para a possibilidade e sucesso da Educação Inclusiva que se criem e sustentem expectativas realistas e positivas sobre os alunos com NEE. Mas não é fácil criar e manter estas atitudes. Durante muitas centenas de anos dedicou-se muito esforço a categorizar e a desvalorizar a diferença e talvez por isso seja difícil alterar este estado de coisas, num período curto de tempo. Uma das estratégias mais bem sucedidas para desenvolver expectativas positivas nos estudantes é proporcionar-lhes contato com pessoas com deficiências. Carrington e Brownlee (2001) analisaram os resultados de um programa de formação que contou com a participação de um professor assistente com paralisia cerebral 
e encontraram uma melhoria significativa nas atitudes dos alunos em relação às capacidades das pessoas com deficiência ao final do curso. Encontramos resultados semelhantes a estes num estudo sobre atitudes de alunos do ensino médio face ao seu professor de Educação Física com tetraplegia (RODRIGUES; LIMA-RODRIGUES, 2011). Existem, igualmente, resultados de investigação sobre a importância da severidade dos casos que são usados na formação. Se, por exemplo, os estudantes tiverem acesso ou estudarem apenas casos com um grau de severidade muito alto, isto pode contribuir para que tenham uma ideia errada sobre a população com que vão trabalhar e, assim, suscitar a criação de atitudes menos positivas. Cook (2001) sugere que as percepções dos estudantes sobre a severidade dos casos com que vão trabalhar influenciam as atitudes que têm face à inclusão de alunos com NEE.

Em resumo, a criação de atitudes positivas encontra-se ligada a três aspectos: 1. Conhecer e discutir casos de "boas práticas" e de sucesso; 2. Estabelecer relações de cooperação com outros elementos de forma a procurar um equilíbrio nas visões sobre o aluno; e 3. Cuidar da formação em serviço para evitar a ancoragem em ideias preconcebidas.

\section{Síntese}

Phillippe Perrenoud (1999) escreveu um livro intitulado "Educação: agir na urgência e decidir na dúvida". Esta frase representa certamente o "pathos" de ser professor: ter de decidir num tempo restrito sem ter um quadro estruturado e inquestionável de dados para fazê-lo. Este é um fato para o qual os estudantes dos cursos de formação de professores devem estar bem preparados. Atuar numa realidade tão premente e desafiante pode convidar a adotar modelos "clínicos" que conduzem a uma falsa sensação de segurança. Pode também conduzir a investir numa vaga "inclusão social", negligenciando as efetivas possibilidades de educação de alunos com dificuldades. Na nossa perspectiva, nenhuma destas opções nos pode levar a um modelo efetivo de Educação Inclusiva.

A Educação necessita de uma reforma no sentido da Inclusão e, para isso, precisa ter os seus próprios agentes, os seus próprios reformadores. Entretanto, em muitos sistemas educacionais - e, certamente, no sistema português - espera-se que os dinamizadores desta reforma a desenvolvam de uma forma, diríamos, "metafísica"; isto é, que devem lutar por uma escola que, na verdade, nunca viram, que nunca experimentaram, e que sejam capazes de adotar métodos diferentes daqueles em que foram educados. É certo que os grandes promoto- 
res da Educação Inclusiva da atualidade nunca experimentaram a Inclusão na sua vida escolar. Chegaram à premência da Educação Inclusiva através do seu próprio convencimento quanto à ética e à justiça da Inclusão. Não deixa de ser estimulante pensar que impulso poderá sofrer a Educação Inclusiva quando esta deixar de ser desenvolvida por pessoas para quem ela não é uma mera opção ética, mas, sim, o resultado de uma experiência pessoal e vivida.

Pensamos que existe uma efetiva responsabilidade de todos os Estados que inscreveram a Educação Inclusiva nos seus programas governamentais e que adotaram a Convenção sobre os Direitos das Pessoas com Deficiência (UN, 2006). Esta responsabilidade conduz a uma reforma séria nos programas de formação de professores em geral e de Educação Especial, em particular, de forma a tornar efetivo o cumprimento do artigo 24 da referida Convenção.

Sabemos, atualmente, quais são os contornos que esta reforma nos sistemas de formação pode e deve assumir: o desenvolvimento de uma "atitude investigativa" que faça da reflexão conjunta uma estratégia indispensável para a melhoria do ensino, que ofereça experiências reais de observação e prática supervisionada, que crie atitudes que contribuam para a sustentabilidade das reformas e a resiliência dos professores.

Precisamos de professores que, com o conhecimento adequado, com atitudes positivas e com um compromisso possam levar adiante a reforma da Educação Inclusiva. Para isso precisamos que a Educação Inclusiva chegue aos cursos de formação de professores. Precisamos de cursos desenvolvidos sob valores Inclusivos para formar professores de Educação Inclusiva. Quando isto acontecer, teremos um valioso e decisivo fator que promova a equidade $\mathrm{e}$ a participação de todos os alunos.

\section{REFERÊNCIAS}

BEN-PERETZ, M. The impossible role of educators on a changing world. Journal of Teacher Education, v. 52, n. 1, p. 48-56, 2001.

BOOTH, T.; AINSCOW, M. Index for Inclusion. Bristol: CSIE, 2001.

BROARDMAN, A. G.; ARDUELLES, M. H.; VAUGHN, S.; HUGHES, M. T.; KLINGNER, J. Special Education Teacher's Views of Research-Based Practices. The Journal of Special Education, v. 39, n. 3, p. 168-180, 2005. 
BURNS, M. K.; YSSELDYKE, J. Reported Prevalence of Evidence-Based Instructional Practices in Special Education. The Journal of Special Education, v. 43, n. 1, p. 3-11, 2009.

CARRINGTON, S.; BROWNLEE, J. Preparing Teachers to Support Inclusion: the benefits of interaction between a group of preservice teachers and a teaching assistant who is disabled. Teaching Education, v. 12, n. 3, p. 347-357, 2001.

COCHRAN-SMITH, M.; LYTLE, S. Relationships of knowledge and practice: Teacher learning in community. Review of Research in Education, n. 24, p. 249-305, 1999.

COOK, B. A comparison of Teachers' Attitudes Toward Their Included Students with Mild and Severe Disabilities. Journal of Special Education, v. 34, n. 4, p. 203-213, Jan. 2001.

DGIDC. Educação inclusiva: da retórica à prática. Lisboa: DGIDC, 2009.

FISHER, D.; FREY, N.; THOUSAND, J. What do Special Educators Need to Know and Be Prepared to Do for Inclusive Schooling to Work. Teacher Education and Special Education, v. 26, n. 1, p. 42-50, 2003.

FLORIAN, L.; ROSE, M. The inclusive practice project in Scotland: Teacher education for inclusive education. Teaching and Teacher Education, v. 25, n. 1, p. 594-601, 2009.

HOPPEY, D.; YENDOL-SILVA, D.; PULLEN, P. C. We became teachers together: Understanding collaborative teaching as innovation in teacher education. Action in Teacher Education, v. 26, n. 1, p. 12-26, 2004.

HUBERMAN, M. The professional cycle of teachers. Teachers College Record 91, v. $37,1989$.

JONES, M. A study of Novice Special Educators Views of Evidence- Based Practices. Teacher Education and Special Education, v. 32, n. 2, p. 101-120, 2009.

KATZ, L. G. Helping others with their teaching. In: KATZ, L. G. Talks with Teachers of Young Children. A Collection. Stamford, CT: Greenwood Publishing, 1995.

; RATHS, James D. Six Dilemmas of Teacher Education. Journal of Teacher Education, v. 43, n. 5, p. 376-385, 1992.

PARRILlA. A.; DANIEL, H. Criação e Desenvolvimento de Grupos de Apoio entre Professores. São Paulo: Loyola, 2003.

PERRENOUD, P. Enseigner: agir dans l'urgence, décider dans l'incertitude. Paris: ESF, 1999.

RODRIGUES, D.; LIMA-RODRIGUES, L. Formar Professores de Educação Física numa Perspectiva Inclusiva In: GAIO, R.; SEABRA Jr., L.; DELGADO, M. A. (Orgs.). Formação Profissional em Educação Física: ações e reflexões. Várzea Paulista: Fontoura, 2011. (no prelo).

RODRIGUES, D. Questões preliminares sobre o desenvolvimento de políticas de Educação Inclusiva. Inclusão - Revista de Educação Especial, v. 4, n. 1, p. 33-40, 2008. 
. Desenvolver a Educação Inclusiva: dimensões do desenvolvimento profissional. In:___. (Ed.). Investigação em Educação Inclusiva, v. II. Lisboa: Fórum de Estudos de Educação Inclusiva, 2007.

SHARMA, U.; FORLIN, F.; LOREMAN T. Impact of training on pre-service teachers' attitudes and concerns about inclusive education and sentiments about persons with disabilities. Disability and Society, v. 23, n. 7, p. 773-785, 2008.

SHULMAN, L. Paradigms and Research Programs in the Study of Teaching: a contemporary perspective. In: AERA. Handbook of Research on Teaching. New York: Collier Macmillan, 1986. p. 3-36.

UNESCO. $48^{\text {th }}$ International Conference on Education - Conclusions and Recommendations. Geneve: IBE, 2008.

UNITED NATIONS. Convention on the Rights of Persons with Disabilities. New York: $\mathrm{UN}, 2006$.

WASBURN-MOSES, L.; ROSENBERG, M. S. Alternative Route Special Education Teacher Preparation Programs Guidelines. Teacher Education and Special Education, v. 31, n. 4 , p. $257-267,2008$.

Texto recebido em 01 de fevereiro de 2011.

Texto aprovado em 05 de abril de 2011. 